\title{
Analisa Spektrum Motor Imagery pada Sinyal Aktivitas Otak
}

\author{
Johan Chandra, Achmad Arifin, dan M. Hilman Fatoni \\ Jurusan Teknik Elektro, Fakultas Teknologi Industri, Institut Teknologi Sepuluh Nopember (ITS) \\ Jl. Arief Rahman Hakim, Surabaya 60111 \\ e-mail: arifin@ee.its.ac.id
}

\begin{abstract}
Abstrak - Otak merupakan organ vital pada tubuh manusia yang berperan sebagai pusat kendali sistem saraf manusia. Sinyal yang dikeluarkan otak (EEG) mengandung berbagai informasi yang dapat dimanfaatkan pada teknologi BCI. Salah satu informasi yang dapat digunakan adalah informasi motorik baik mengenai motor execution maupung motor imagery. Pada penderita stroke yang biasanya mengalami kelumpuhan pada anggota gerak tubuhnya, informasi mengenai motor imagery dapat dimanfaatkan untuk aplikasi Brain Computer Interface terutama dalam rehabilitasi kelumpuhan anggota gerak pasien tersebut. Pada penelitian ini dirancang sebuah alat sistem EEG untuk merekam sinyal EEG pada otak untuk menganalisa spektrum motor imagery pada sinyal aktivitas otak. Sistem terdiri dari rangkaian filter pasif, rangkaian proteksi, penguat isntrumentasi, common mode rejection, amplifier, dan filter. Pengujian dilakukan dengan membandingkan sinyal EEG pada tasking motor imagery dan motor execution. Selanjutnya, informasi motorik baik motor execution dan motor imagery dapat diaplikasikan lebih lanjut pada sistem BCI terutama pada rehabilitasi medik.
\end{abstract}

Kata Kunci-EEG, Motor Imagery, Motor Execution, Upper Limb Segment

\section{PENDAHULUAN}

$\mathrm{S}$ TROKE merupakan salah satu penyakit berbahaya yang menyebabkan fungsi otak terganggu akibat terhambatnya suplai darah ke otak. Pasca terjadinya stroke, seseorang biasanya mengalami kelumpuhan pada anggota tubuhnya, terutama anggota gerak tubuh seperti tangan dan kaki. Meski demikian, sinyal kelistrikan atau aktivitas di otak secara motorik masih berfungsi dengan baik terutama saat membayangkan gerakan atau saat akan menggerakkan anggota gerak tubuhnya [1]. Informasi berupa sinyal kelistrikan pada otak/ Electroencephalogram ini dapat dimanfaatkan untuk aplikasi Brain Computer Interface terutama dalam rehabilitasi kelumpuhan anggota gerak pasien tersebut.

Langkah yang dapat dilakukan untuk mengembalikan fungsi motorik anggota gerak pada pasien stroke dapat dilakukan dengan penggunaan Functional Electrical Stimulation. Control command untuk mengontrol FES bisa didapatkan menggunakan teknologi BCI dengan memanfaatkan informasi motorik pada sinyal EEG dari pasien [2]. Saat pasien menghendaki gerakan pada anggota gerak tertentu, maka sinyal EEG dapat diidentifikasi pada bagian Motor Area yang aktif seperti, Primary Motor Cortex, Supplementary Motor Area, dan Premotor Cortex [3].
Dengan menganalisa sinyal EEG pada Motor Area, akan didapatkan informasi mengenai Motor Imagery. Dari proses ini, sinyal EEG diproses dan diekstrak untuk mendapatkan parameter-parameter yang dapat digunakan untuk mengidentifikasi gerakan yang dibayangkan subjek. Informasi tersebut dapat digunakan pada aplikasi BCI lebih lanjut.

\section{METODE PENELITIAN}

\section{A. Diagram Blok Sistem}

Secara umum, sistem terdiri dari perangkat keras dan perangkat lunak. Perangkat keras berupa sistem instrumentasi EEG dan mikrokontroler STM32F407VG.

Sedangkan perangkat lunak terdiri dari program berupa filter digital, analisa sinyal dalam domain frekuensi (DFTFFT), analisa sinyal dalam domain waktu-frekuensi (STFTCWT), power spectrum, energy, RMS untuk mengidentifikasi motor imagery.

\section{B. Perancangan Perangkat Elektronik}

\section{- Passive Filter}

Filter pasif merupakan rangkaian paling awal pada rangkaian instrumentasi EEG. Filter pasif ini berupa low pass filter orde 1 dengan frekuensi cut-off $160 \mathrm{~Hz}$. Filter pasif ini berfungsi meredam sinyal dengan frekuensi tinggi diatas 160 $\mathrm{Hz}$, karena setiap rangkaian penguat operasional memiliki parameter Gain Bandwidth.

\section{- Protection Circuit}

Rangkaian proteksi ini berfungsi untuk membatasi sinyal input yang dapat masuk ke rangkaian istrumentasi sebesar 9V dan $-9 \mathrm{~V}$. Ketika tegangan input lebih besar dari $9 \mathrm{~V}$ atau lebih kecil dari $-9 \mathrm{~V}$, maka diode akan aktif secara

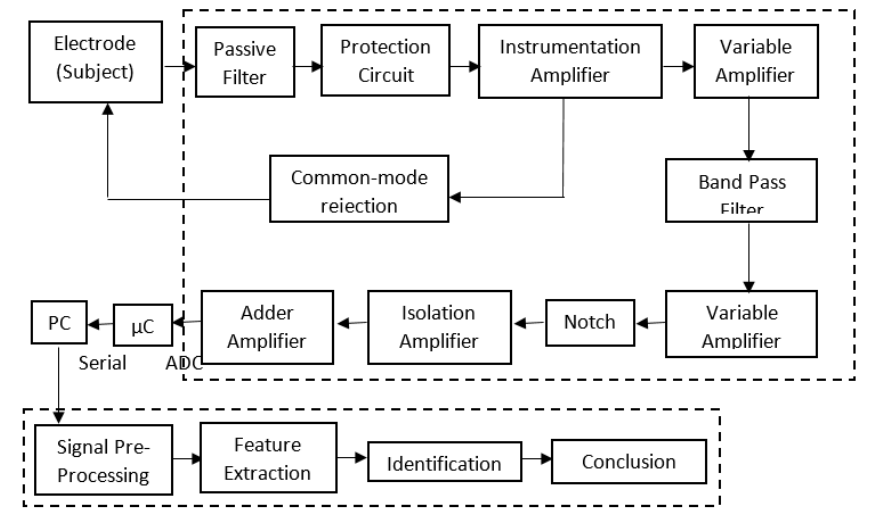

Gambar 1 Diagram Blok Sistem Secara Keseluruhan 
otomatis sehingga tegangan input pada kaki (+) dan (-) instrumentasi adalah $\pm 9 \mathrm{~V}$.

\section{- Instrumentation Amplifier}

Secara keseluruhan, rangkaian instrumentation amplifier ini terdiri dari 2 blok utama.

Blok pertama adalah IC INA128 yang berfungsi sebagai penguat instrumen. CMRR pada IC ini mencapai $100 \mathrm{~dB}$ saat penguatan $G=10.68$. IC penguat instrumen ini dipilih karena memiliki spesifikasi yang sangat baik dan karakteristik yang tepat untuk sinyal EEG dibanding IC penguat instrumen lainnya.

Penguatan pada penguat instrumentasi ini dirancang tidak terlalu besar yaitu sekitar 10.68 kali. Penguatan tidak dapat diatur terlalu besar akibat komponen DC [9].

Blok kedua adalah rangkaian yang dikenal sebagai common mode rejection untuk mengurangi noise dengan memberikan feedback ke tubuh subjek. Rangkaian ini memberikan tegangan ke permukaan kulit untuk meminimalisir interferensi common mode pada tubuh dan menguatkan sinyal.

\section{- Main Amplifier}

Sinyal EEG memiliki amplitudo yang sangat kecil. Setelah melalui rangkaian penguat instrumentasi dengan penguat sekitar 10 kali, sinyal keluarannya masih terlalu kecil, memiliki banyak noise, dan belum mencukupi untuk analisa dan pengambilan data. Sehingga sinyal EEG perlu dikuatkan dengan penguatan multi-stage.

Penguatan pada main amplifier adalah sebesar 53.7 kali. Selain berfungsi sebagai penguat, pada blok rangkaian ini terdapat kapasitor dan resistor berfungsi sebagai low pass filter orde satu untuk meredam sinyal diatas $100 \mathrm{~Hz}$.

\section{- Band Pass Filter}

\section{○ Low Pass Filter}

Rangkaian LPF yang dirancang adalah filter Butterworth order 2 dengan topologi Sallen-Key. Rangkaian ini berfungsi mereduksi sinyal dari interferensi gelombang RF dan menghindari anti-aliasing saat proses sampling sinyal. Low Pass Filter dirancang dengan frekuensi cutoff sebesar $68 \mathrm{~Hz}$. Nilai R dan C dapat dicari dari persamaan (1).

\section{○ High Pass Filter}

Rangkaian HPF yang dirancang adalah filter Butterworth order 2 dengan topologi Sallen-Key. Rangkaian ini berfungsi mereduksi sinyal dari interferensi sinyal listrik otot dan sinyal DC drift berfrekuensi rendah. High Pass Filter dirancang dengan frekuensi cutoff sebesar $0.23 \mathrm{~Hz}$. Nilai R dan $\mathrm{C}$ dapat dicari dari persamaan 2 .

\section{- Variable Amplifier}

Blok rangkaian variable amplifier berfungsi sebagai penguat tahap akhir pada rangkaian agar sinyal EEG memiliki amplitudo yang cukup untuk proses sampling dengan ADC. Hal ini perlu dilakukan karena subjek yang berbeda memiliki range sinyal EEG yang berbeda pula. Sinyal EEG pada blok ini dikuatkan dengan penguatan berbeda menggunakan resistor multiturn. Pada blok variable amplifier, penguatan ditetapkan sebesar 40 kali untuk menguatkan sinyal EEG yang telah dikuatkan 10.68 kali pada tahap pertama dan 53.7 kali pada tahap kedua.

\section{- Notch Filter}

Rangkaian Notch Filter berfungsi mereduksi sinyal yang berasal dari interferensi jala-jala berfrekuensi $50 \mathrm{~Hz}$. Rangkaian notch filter dirancang dengan konfigurasi Twin-T dengan frekuensi resonansi $50 \mathrm{~Hz}$.

\section{- Isolation Amplifier}

Rangkaian isolation amplifier merupakan rangkaian isolasi antara EEG dengan PC agar subjek aman dari kemungkinan adanya arus balik. Desain rangkaian isolation amplifier yang digunakan adalah optical insulation. Rangkaian ini memanfaatkan 2 buah optocoupler untuk mentransmisikan sinyal antara kedua rangkaian secara terpisah.

\section{- Non-Inverting Adder Amplifier}

Rangkaian Adder Amplifier berfungsi menambah level tegangan sinyal EEG agar mencukupi untuk proses sampling dengan ADC. Range dari ADC internal mikrokontroler STM32F407VG adalah 0-3.3V. Sehingga diperlukan adanya rangkaian adder amplifier untuk menambahkan sinyal offset sebesar 2 Volt agar sinyal EEG dapat terekam dari puncak atar hingga puncak bawah.

\section{Perancangan Perangkat Lunak}

\section{- Continuous Wavelet Transform}

CWT adalah metode untuk dekomposisi sinyal dalam domain waktu dan frekuensi. Sinyal input $\mathrm{x}(\mathrm{t})$ dikonvolusi dengan fungsi window. Pada penelitian ini digunakan CWT dengan fungsi window mother wavelet. Persamaan CWT didapatkan dengan

$C W T_{x}^{\psi}(\tau, s)=\psi_{x}^{\psi}(\tau, s)=\frac{1}{\sqrt{|s|}} \int_{-\infty}^{\infty} x(t) \cdot \psi^{*}\left(\frac{t-\tau}{s}\right) d t$

dimana $\tau$ adalah time shift yang menunjukkan translasi dari mother wavelet dan s adalah skala. Fungsi window mother wavelet disimbolkan sebagai $\psi^{*}$ dengan jenis complex morlet. Morlet merupakan fungsi dari Gaussian yang termodulasi oleh eksponensial kompleks. Fungsi morlet mother wavelet didapatkan dengan

$$
\psi^{*}(t)=\pi^{-1 / 4} \cdot e^{-j \omega_{0} t} \cdot e^{-t^{2} / 2}
$$

dimana nilai $\omega_{0}$ sama dengan $2 \pi f_{0}$ dan $f_{0}$ sebesar 0,849 .

Parameter skala dapat ditransformasikan menjadi parameter frekuensi dengan persamaan

$$
f=\frac{f c}{s}
$$

dimana fc adalah frekuensi pusat setiap skala s yang nilainya sama dengan $\mathrm{f}_{0}$. Pada penelitian ini, nilai skala yang digunakan adalah $10^{-3}$ dengan langkah sebesar $10^{-3}$.

\section{HASIL PENGUKURAN DAN ANALISA}

\section{A. Pengujian Alat Keseluruhan}

Pengujian sistem EEG secara keseluruhan dilakukan dengan mengukur sinyal EEG pada scalp kepala menggunakan sistem yang dirancang. Pengujian dilakukan dengan membandingkan hasil pengukuran pada titik C3 dan C4 pada scalp kepala dengan tasking motor imagery. Ilustrasi tasking motor imagery dapat dilihat pada gambar 13. Satu sesi perekaman berdurasi 25 detik. 


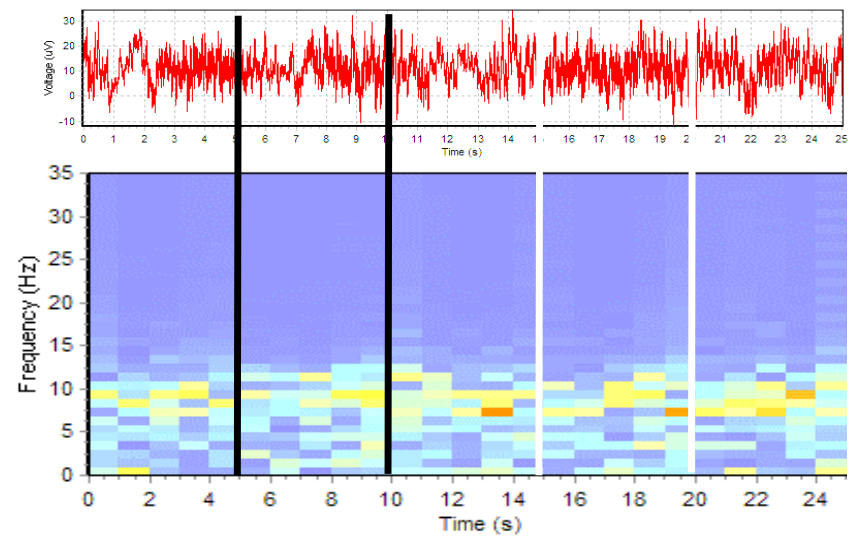

Gambar 2 Hasil perekaman pada titik C3 subjek 1 pada domain waktufrekuensi dengan sistem yang dirancang

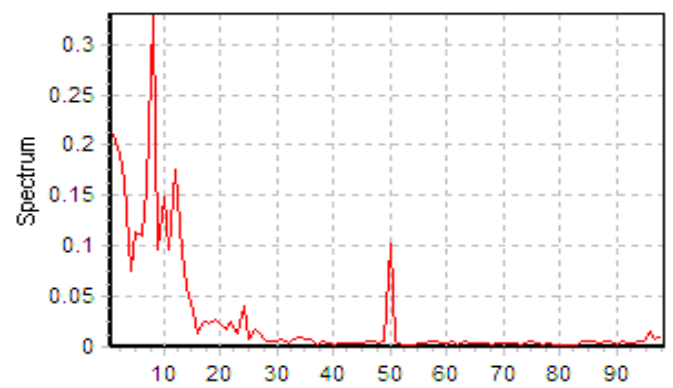

Gambar 3 Hasil DFT sinyal terekam dengan sistem yang dirancang

Dari hasil pengukuran, didapatkan bahwa sinyal EEG yang terekam memiliki karakteristik yang sama yaitu random dan chaos serta berfrekuensi rendah. Dari hasil pengujian didapatkan bahwa rangkaian yang dirancang mampu menangkap sinyal EEG dengan baik ditandai dengan aktivitas motorik yang ditunjukkan perubahan spektrum frekuensi pada rentang alfa $(7-13 \mathrm{~Hz})$ pada plotting dalam domain waktufrekuensi. Selain itu, noise dan frekuensi jala-jala dapat diminimalisir dengan baik.

\section{B. Perbandingan Motor Imagery dengan Motor Execution}

Pengujian sistem EEG yang dirancang dilakukan untuk membandingkan aktivitas motorik saat terjadinya motor execution dengan motor imagery. Selama proses perekaman, tasking yang diberikan memiliki durasi yang sama yaitu 25 detik tiap sesi.

Tabel 1

Amplitudo sinyal rata-rata EEG pada 4 subjek saat motor execution di titik C3

\begin{tabular}{|c|c|c|c|c|c|c|}
\hline \multirow{3}{*}{ Subjek } & \multicolumn{6}{|c|}{ C3 } \\
\hline & \multicolumn{2}{|c|}{ Relax } & \multicolumn{2}{|c|}{ Kiri } & \multicolumn{2}{|c|}{ Kanan } \\
\hline & Min & Max & Min & Max & Min & Max \\
\hline 1 & -6.0155 & 19.36798 & -12.3885 & 23.00386 & -11.0369 & 26.92358 \\
\hline 2 & -54.201 & 43.39526 & -36.8462 & 52.25306 & -38.7858 & 46.73166 \\
\hline 3 & 7.8001 & 46.62162 & 7.80018 & 50.36654 & 6.72538 & 51.1642 \\
\hline 4 & -6.9076 & 27.95082 & -15.9334 & 34.39992 & -10.2079 & 32.64914 \\
\hline
\end{tabular}

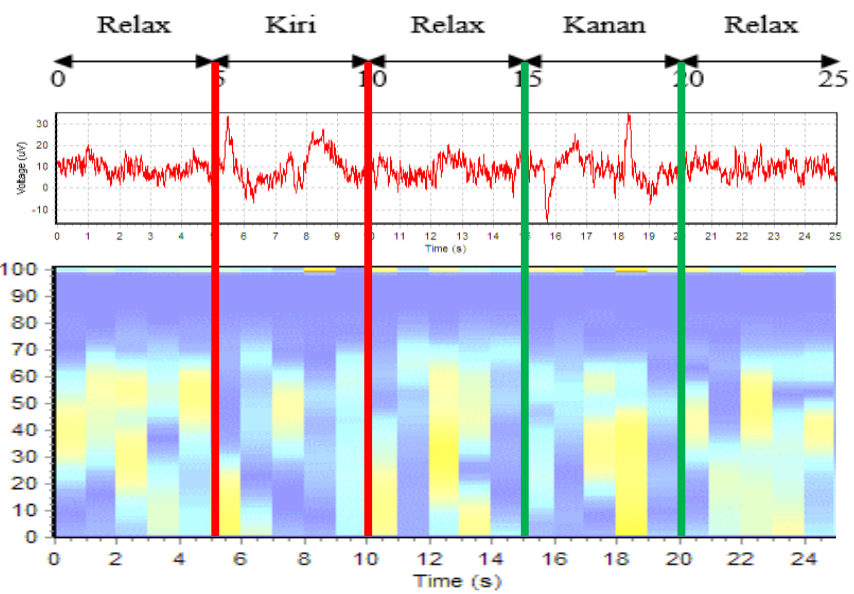

Gambar 4 Hasil pengukuran sinyal EEG dalam domain waktu dan waktufrekuensi menggunakan CWT saat tasking motor execution

Dari hasil pengukuran sinyal saat motor execution, terlihat pada sinyal raw EEG bahwa terjadi perubahan sinyal saat subjek menggerakkan tangan baik tangan kiri maupun tangan kanan. Hal ini dapat diamati dengan menganalisa amplitudo minimal dan maksimal sinyal seperti pada tabel 1 dan 2. Pada saat terjadi gerakan, amplitudo minimum dan maksimum mengalami perubahan signifikan dibandingkan saat kondisi relaks. Selain itu, pada plotting sinyal dalam domain waktufrekuensi, didapatkan bahwa saat terjadi tasking, terjadi penurunan dan peningkatan power spectrum (ERD/ERS) pada rentang frekuensi alfa seperti pada gambar 18.

Hasil pengujian pada tasking motor imagery menunjukkan perbedaan dengan tasking motor execution. Pada tasking motor imagery, tidak terdapat perubahan signifikan pada amplitudo maksimum dan minimum dari raw signal. Amplitudo sinyal cenderung konstan baik saat kondisi relax maupun terdapat bayangan gerakan tangan seperti data pada tabel 3 dan 4.

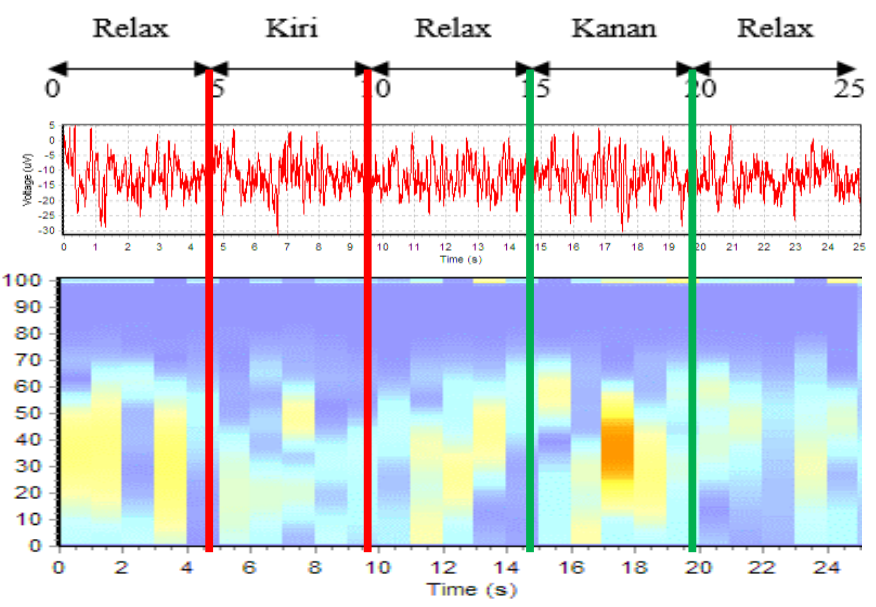

Gambar 5 Hasil pengukuran sinyal EEG dalam domain waktu dan waktufrekuensi menggunakan CWT saat tasking motor imagery

Tabel 2

Amplitudo sinyal rata-rata EEG pada 4 subjek saat motor execution di titik $\mathrm{C} 4$

C4

Subjek

Relax Kiri

Kanan 


\begin{tabular}{rrrrrrl}
\cline { 2 - 6 } & \multicolumn{1}{c}{ Min } & \multicolumn{1}{c}{ Max } & \multicolumn{1}{c}{ Min } & \multicolumn{1}{c}{ Max } & \multicolumn{1}{c}{ Min } & Max \\
\hline 1 & -8.8201 & 12.2787 & -10.5435 & 16.2795 & -13.5779 & 19.8208 \\
2 & -43.847 & 42.3865 & -32.4399 & 50.5303 & -41.1511 & 44.2068 \\
3 & 9.6118 & 47.2435 & 6.2657 & 48.676 & 2.8722 & 52.8744 \\
4 & -13.99 & 37.141 & -14.7437 & 37.74602 & -12.0668 & 37.9217 \\
\hline \hline
\end{tabular}

Tabel 3

Perbandingan MPF pada 4 Subjek saat Motor Execution

\begin{tabular}{ccccccc}
\hline \hline \multirow{2}{*}{ Subjek } & \multicolumn{3}{c}{ C3 } & & \multicolumn{3}{c}{ C4 } \\
\cline { 2 - 7 } & Relax & Kiri & Kanan & Relax & Kiri & Kanan \\
\hline 1 & 10.21156 & 8.4681 & 8.63287 & 10.40595 & 8.72908 & 9.222418 \\
2 & 10.3905 & 9.625 & 9.483756 & 10.8207 & 9.464238 & 8.91684 \\
3 & 11.83598 & 11.0571 & 11.97562 & 11.73652 & 11.14063 & 11.13442 \\
4 & 9.475 & 8.2160 & 7.75888 & 11.43036 & 11.36092 & 10.05508 \\
Mean & 10.47826 & 9.3415 & 9.462782 & 11.09838 & 10.17372 & 9.83219 \\
\hline \hline
\end{tabular}

Tabel 4

Amplitudo sinyal rata-rata EEG pada 4 subjek saat motor imagery

\begin{tabular}{|c|c|c|c|c|c|c|}
\hline \multirow{3}{*}{ Subjek } & \multicolumn{6}{|c|}{ C3 } \\
\hline & \multicolumn{2}{|c|}{ Relax } & \multicolumn{2}{|c|}{ Kiri } & \multicolumn{2}{|c|}{ Kanan } \\
\hline & Min & Max & Min & Max & Min & Max \\
\hline 1 & -22.0121 & 38.1353 & -26.9928 & 37.29056 & -30.189 & 37.1146 \\
\hline 2 & -38.0896 & 39.0476 & -17.713 & 38.0542 & -37.778 & 42.1834 \\
\hline 3 & -11.188 & 36.7726 & -17.407 & 35.8059 & -13.729 & 35.0962 \\
\hline 4 & -5.1099 & 28,3833 & -6.0493 & 28.6672 & -8.3471 & 26.2545 \\
\hline
\end{tabular}

Tabel 5

Amplitudo sinyal rata-rata EEG pada 4 subjek saat motor imagery

\begin{tabular}{ccccccc}
\hline \hline \multirow{2}{*}{ Subjek } & \multicolumn{6}{c}{ C4 } \\
\cline { 2 - 7 } & \multicolumn{2}{c}{ Relax } & \multicolumn{2}{c}{ Kiri } & \multicolumn{2}{c}{ Kanan } \\
\cline { 2 - 7 } & Min & Max & \multicolumn{1}{c}{ Min } & Max & Min & Max \\
\hline 1 & -18.5924 & 32.4785 & -22.4174 & 28.6198 & -21.2348 & 26.045 \\
2 & -34.1429 & 30.9987 & -15.4634 & 30.2215 & -23.4988 & 28.5658 \\
3 & -3.9415 & 27.7077 & -10.0997 & 29.2827 & -10.8906 & 32.3382 \\
4 & -22.7013 & 48.6509 & -22.7757 & 43.704 & -20.7415 & 45.1164 \\
\hline \hline
\end{tabular}

Tabel 6

Perbandingan MPF pada 4 Subjek saat Motor Imagery

\begin{tabular}{ccccccc}
\hline \hline \multirow{2}{*}{ Subjek } & \multicolumn{3}{c}{ C3 } & & \multicolumn{3}{c}{ C4 } \\
\cline { 2 - 7 } & Relax & Kiri & Kanan & Relax & Kiri & Kanan \\
\hline 1 & 8.2292 & 8.33359 & 8.2621 & 8.0575 & 8.72306 & 8.6629 \\
2 & 8.86818 & 9.82048 & 8.7913 & 8.51017 & 9.32964 & 8.90684 \\
3 & 8.361224 & 8.51762 & 8.247 & 9.4367 & 8.80332 & 9.37388 \\
4 & 8.9414 & 9.1145 & 9.1859 & 11.0561 & 11.8845 & 11.107 \\
Mean & 8.6001 & 8.94654 & 8.6215 & 9.2651 & 9.68513 & 9.512678 \\
\hline \hline
\end{tabular}

Hanya saja, pada plotting sinyal dalam domain waktufrekuensi menggunakan CWT, didapatkan bahwa terjadi perubahan power spectrum pada rentang frekuensi alfa (7-13 $\mathrm{Hz}$ ) saat subjek diberi tasking untuk membayangkan gerakan tangannya terutama pada saat instruksi tangan kanan seperti terlihat pada gambar 19.

\section{KESIMPULAN}

Dari perancangan, realisasi, dan pengujian pada tugas akhir ini didapatkan beberapa kesimpulan untuk perangkat keras dan lunak. Dari sisi perangkat keras, penguatan yang digunakan untuk menguatkan sinyal EEG adalah sebesar 23842 kali yang terbagi ke dalam tiga stage penguatan untuk menghindari penguatan yang terlalu besar pada tiap stagenya. Frekuensi cut-off pada low pass filter sebesar $68 \mathrm{~Hz}$, frekuensi cut-off high pass filter sebesar $0.56 \mathrm{~Hz}$, frekuensi resonansi notch filter sebesar $50 \mathrm{~Hz}$, tegangan offset pada non-inverting adder amplifier sebesar 1 Volt, dan frekuensi sampling sebesar 200 Hz. Rangkkaian instrumentasi yang dirancang dapat merekam sinyal EEG dengan baik dan mampu menangani interferensi sinyal noise serta jala-jala listrik.

Pada tasking motor execution, terdapat perubahan signifikan pada nilai amplitudo sinyal EEG di titik C3 dan C4. Perubahan yang dihasilkan memiliki karakteristik yang sama di kedua titik dan memiliki konsistensi setiap adanya event menggerakkan tangan. Selain itu, saat sinyal diamati dalam domain waktu-frekuensi, didapatkan bahwa terjadi peningkatan maupun penurunan power spectrum pada rentang frekuensi $7-13 \mathrm{~Hz}$ (ERD/ ERS). Pada tasking motor imagery perubahan pada sinyal EEG saat subjek membayangkan gerakan tangan cenderung tidak terlihat pada plotting sinyal dalam domain waktu. Namun, pada analisa dalam domain waktu-frekuensi, terlihat aktivitas dominan pada rentang 7-13 $\mathrm{Hz}$ seperti pada tasking motor execution ditandai dengan peningkatan dan penurunan power spectrum. Hanya saja pola yang ditunjukkan berbeda pada dua kondisi tersebut. Pola tersebut dapat dimanfaatkan lebih lanjut pada aplikasi BCI.

\section{DAFTAR PUSTAKA}

[1]Lotze, Martin. Halsband, Ulrike, "Motor Imagery". Journal of Physiology, Paris, vol. 99. Pp.386-395, 2006.

[2]Pfurtscheller, G. Silva, F.H. Lopes da, "Event-related EEG/MEG synchronization dan desynchronization: basic principles". Clinical Neurophysiology 110. Pp 1842-1857, 1999.

[3]Cortical Functions Reference, Trans Cranial Technologies ldt, Hong Kong, 2012. 